\title{
Correction to: Genetic and Clinical Predictors of Ataxia in Pediatric Primary Mitochondrial Disorders
}

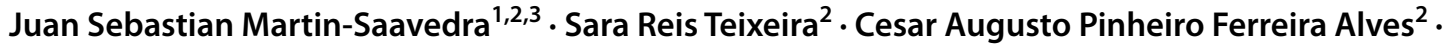 \\ Fabrício Guimarães Gonçalves ${ }^{2} \cdot$ Luis Octavio Tierradentro-Garcia $^{2} \cdot$ Martin Kidd $^{4}$. Colleen Muraresku ${ }^{5}$. \\ .Amy Goldstein ${ }^{5,6} \cdot$ Arastoo Vossough $^{2,7}$
}

Published online: 26 January 2022

○) Springer Science+Business Media, LLC, part of Springer Nature 2022

\section{Correction to: The Cerebellum https://doi.org/10.1007/s12311-021-01276-1}

In the original manuscript, the authors want to correct the declared funding for two of the authors. Collen Murasesku $(\mathrm{CM})$ and Amy Goldstein (AG) in fact did NOT receive support for this paper from National Institutes of Health (U24-HD093483 to Marni J. Falk, MD).

The original paper has been corrected.

Publisher's Note Springer Nature remains neutral with regard to jurisdictional claims in published maps and institutional affiliations.

The original article can be found online at https://doi.org/10.1007/ s12311-021-01276-1.

Juan Se bastian Martin-Saavedra

jm4785@drexel.edu

1 Department of Pediatrics, St. Christopher's, Hospital for Children, 160 E Erie Ave, Philadelphia, PA, USA

2 Division of Neuroradiology, Department of Radiology, Children's Hospital of Philadelphia, Philadelphia, PA, USA

3 Clinical Research Group, Escuela de Medicina Y Ciencias de La Salud, Universidad del Rosario, Bogota, DC, Colombia

4 Centre for Statistical Consultation, Stellenbosch University, Stellenbosch, South Africa

5 Division of Human Genetics, Department of Pediatrics, Mitochondrial Medicine Frontier Program, Children's Hospital of Philadelphia, Philadelphia, PA, USA

6 Department of Pediatrics, University of Pennsylvania Perelman School of Medicine, Philadelphia, PA, USA

7 Department of Radiology, University of Pennsylvania Perelman School of Medicine, Philadelphia, PA, USA 